Article

\title{
National Hazards Vulnerability and the Remediation, Restoration and Revitalization of Contaminated Sites- 2. RCRA Sites
}

\author{
Kevin Summers *, Andrea Lamper and Kyle Buck \\ Gulf Ecosystem Measurement and Modeling Divison, U.S. Environmental Protection Agency, \\ Gulf Breeze, FL 32561, USA; lamper.andrea@epa.gov (A.L.); buck.kyle@epa.gov (K.B.) \\ * Correspondence: summers.kevin@epa.goc; Tel.: +1-850-934-9244
}

check for

updates

Citation: Summers, K.; Lamper, A.; Buck, K. National Hazards

Vulnerability and the Remediation,

Restoration and Revitalization of

Contaminated Sites-2. RCRA Sites.

Sustainability 2021, 13, 965.

https://doi.org/10.3390/su13020965

Received: 17 December 2020

Accepted: 15 January 2021

Published: 19 January 2021

Publisher's Note: MDPI stays neutral with regard to jurisdictional claims in published maps and institutional affiliations.

Copyright: (c) 2021 by the authors. Licensee MDPI, Basel, Switzerland. This article is an open access article distributed under the terms and conditions of the Creative Commons Attribution (CC BY) license (https:// creativecommons.org/licenses/by/ $4.0 /)$.

\begin{abstract}
Natural hazards can be powerful mechanisms that impact the restoration of Resource Conservation and Recovery Act (RCRA) contaminated sites and the community revitalization associated with these sites. Release of hazardous materials following a natural hazard can impact communities associated with these sites by causing the release of hazardous or toxic materials. These releases can inhibit the restoration of the sites, thus altering the long-term sustainable community revitalization. Hazard-related contaminant releases in areas characterized by large populations can create problems equal to those posed by the original site clean-up. Similarly, natural hazards can enhance the probability of future issues associated with the renovated sites. This manuscript addresses the co-occurrence of 12 natural hazards (singly and in combination) at individual RCRA sites. The co-occurrence was determined by the co-location of exposure likelihoods determined from the Cumulative Resilience Screening Index (CRSI) and the site locations for RCRA facilities provided by Environmental Protection Agency. Results showed that several natural hazards were likely to occur at RCRA facilities and these occurrences should be included in management and policy evaluations of these sites.
\end{abstract}

Keywords: RCRA; natural hazards; exposure; hazardous releases; non-hazardous releases

\section{Introduction}

Natural hazard events (e.g., hurricanes, tornadoes, wildfires, earthquakes) can increase the probability of releases from contaminated sites (e.g., landfills, solid waste contaminants). These releases can threaten human health and the environment by exposing individuals directly to hazardous materials or indirectly to secondary hazards (e.g., explosions, fires) when flammable materials are impacted [1]. Releases of hazardous materials from contaminated Resource Conservation and Recovery Act (RCRA) sites have been documented after hurricanes [2,3], wildfires [4-6], earthquakes [7-9], and floods [10,11].

The Resource Conservation and Recovery Act (RCRA) describes a framework for the proper management of hazardous and non-hazardous solid waste [12]. Solid waste includes solids, liquids, and gases and must be discarded to be considered waste [13]. The U.S. Environmental Protection Agency (EPA) defines "solid waste" as "any garbage or refuse, sludge from a wastewater treatment plant, water supply treatment plant, or air pollution control facility and other discarded material, resulting from industrial, commercial, mining, and agricultural operations, and from community activities" [12]. This law creates the waste management program that gives EPA authority to develop the RCRA program. The term RCRA often refers to interchangeably to the law, regulations, and EPA policy and guidance. The difference is that EPA regulations carry out the congressional intent by providing explicit, legally enforceable requirements for waste management. These regulations can be found in Title 40 of the Code of Federal Regulations (CFR), parts 239 through 282 [12]. EPA guidance documents and policy directives clarify issues related to the implementation of the regulations. 
In addition to site contamination management and remediation, the RCRA program does not only seek to clean up sites-the program aims to return these sites to productive and sustainable use serving their local community [14]. Remediation, restoration, or revitalization is incomplete unless it is sustainable and resilient. RCRA restoration plans for hazardous and non-hazardous waste sites must include potential impacts stemming from exposure to natural hazards like sea level rise, tornadoes, flooding, wildfires, and hurricanes [15]. Estimating site exposures during management and restoration is critical for the sustainability and revitalization of communities. For these reasons, the present study was undertaken in order to provide the basic natural hazard exposure information for each RCRA site; thus, allowing better and more sustainable management of the sites and more complete restoration plans. The Cumulative Resilience Screening Index (CRSI) provides these types of natural hazard exposure information. The CRSI and the methodologies for estimating risk based on exposure for natural hazard events have been described in detail in Summers et al. [16-19]. The CRSI examines the history of natural hazard events throughout the United States as well as the environmental, economic, governance, and social characteristics associated with resilience to these events. Twelve (12) natural hazards were selected from a review of the 100 Resilient Cities Report [20] and the National Climate Assessment [21] and are included in the CRSI:

- Drought

- High Winds

- Coastal Flooding

- Inland Flooding

- Wildfires

- Earthquakes
- Hurricanes

- Tornadoes

- Landslides

- Hail

- $\quad$ Extreme Low Temperatures

- $\quad$ Extreme High Temperatures

This manuscript examines the probability of RCRA site exposure to one or more of these natural hazards during management, restoration, and afterward when the site is being incorporated into community revitalization efforts. In the development of the CRSI model [17-19], the risk domain includes metrics which describe the spatial and temporal impact of these natural hazards. There is extensive research examining the impact of extreme weather events on the management of contaminated and remediated sites [22]. Violent storms, fires, hail, earthquakes, and landslides pose structural threats to sites that could slow clean-up or cause subsequent releases [23,24]. Drought, floods, and temperature extremes can alter the transport of chemicals or change their bioavailability in the environment $[25,26]$. Knowledge of potential exposures can help planning for and mitigation of future hazard exposures, potentially limiting the vulnerability of communities nearby. Exposure to one or more of the hazards during restoration or community revitalization could present a significant problem involving potential re-exposure to the contaminants involved with the sites.

A database is created to include locations of all active RCRA sites (with some exceptions due to data availability), natural hazards exposure information, and the concurrence of hazards with RCRA sites. The objective of the assessment is to address the challenges for restoration and revitalization resulting from natural hazard exposures at contaminated sites for all (or as many as possible) counties in the United States.

\section{Methods}

The approach consists of six steps which focus on the extraction of relevant information from existing data sources, joining these datasets based on a common spatial unit, collapsing the merged data set into representative units (quartiles) based on normalized exposure data, and mapping the resulting information. The steps include:

(1) Location and extraction of the latest RCRA site information (name and location) from EPA's Facility Registry Service (FRS) for all active sites [12];

(2) Location and extraction of the 2018 county boundary and 2015 core-based statistical area information with population estimates from the US Census; 
(3) Location and extraction of 2000-2015 natural hazard exposure information for the twelve natural hazards listed above from the EPA's Cumulative Resilience Screening Index (CRSI) database [19];

(4) Normalization of exposure estimates for each type of natural hazard on a 0-100 scale (data were reviewed to ascertain if outliers were present which might skew the distribution; no outliers were determined);

(5) Merging of these sets of information based on a common spatial scale (i.e., county); and,

(6) Mapping of the merged information to depict the RCRA site location with the highest exposure for each hazard type and the integration of all twelve hazards, and potential level of impact of the highest exposures at core-based statistical areas of varying population.

Natural hazard exposure estimates in this study are created from the Patterns of Risk using an Integrated Spatial Multi-Hazard (PRISM) approach [27], which was used in the construction of risk domain in the original CRSI $[17,19]$. This approach creates spatial extents for each hazard-type using historic and modeled data from 2000-2015. Data from the National Land Cover Database (NLCD) is used to estimate natural hazard exposures associated with land cover types [28]. Land-area hazard exposures are modeled at the county level and combined to represent multi-hazard exposure probability. The data created represents proportional county acreage exposed to natural hazards, which serves as a proxy for multi-hazard vulnerability. These county exposure estimates form the base metrics of the CRSI risk domain and are used here to approximate the location of natural hazards across the US.

Spatial data for RCRA sites on the National Registry List were retrieved from the EPA's Facility Registry Service (https: / / www.epa.gov / frs / geospatial-data-download-service; last updated 2020). All active sites were joined to their respective county and CoreBased Statistical Areas (CBSAs) (https: / / www2.census.gov/programs-surveys/popest/ datasets/2010--2015/metro/totals/), enabling county hazard exposure metrics and relevant demographic data to be combined with the RCRA sites for analysis. Only 1057 out of the $455,478(<0.2 \%)$ defined active US RCRA sites were removed because they either did not have complete corresponding latitude and longitude data or they were not located in a US county. Additionally, 165 RCRA were excluded (primarily in Alaska) due to a lack of CRSI data. The final output, which contained 454,256 active RCRA sites with CRSI exposure estimates, was brought back into ArcMap for mapping purposes.

Hazard vulnerability is attributed to RCRA sites through both the assessment of potential population impacts (population vulnerability) and exposure probability (site vulnerability). In both conceptualizations, vulnerability represents the likelihood of harm resulting from an exposure. A higher probability of exposure at an RCRA site (i.e., higher metric score) translates to higher vulnerability. Similarly, a high population density surrounding an active RCRA site will increase the likelihood of health impacts following a release. Site vulnerability is represented for each hazard as a score (1-99), where the original land proportion exposures from the county are converted to a scaled estimate of exposure likelihood based on a distribution of values after normalization.

To investigate the potential multi-hazard exposure of active RCRA sites within the U.S., the minimum, maximum, and quartiles were calculated for each of the twelve metric natural hazard scores to represent magnitude of exposure. Each score for each natural hazard exposure-RCRA site combination was "binned" to represent the magnitude of potential exposure. For example, if a site had a metric score of 63 for hurricane exposure, then that site would receive a "binned score" of 3 (i.e., score between 50-75) because it fell into the third scoring class. While the scoring classes were the same for each hazard (i.e., 0-25, 25-50, 50-75, and 75-100), the breakpoints for each natural hazard (i.e., number of RCRA sites in each bin) were different. Similarly, total exposure at each site was determined by summing the total number of hazard exposure types that fell into the third or fourth "bin". For example, a site with a high probability of exposure to hurricanes, wildfires, earthquakes, and drought and would receive a final cumulative exposure score of 4 . 
The 2015 population estimate data per CBSA were mapped in relation to sites with potentially high exposure to multiple hazards. Definition queries within ArcMap (https:/ / desktop.arcgis.com/en/arcmap/) were used to limit the 917 CBSAs to specified population ranges, these being: 0-50,000,50,000-250,000, 250,000-1,000,000, and 1,000,000+.

Few assumptions were made in the mapping effort beyond the information being mapped was correct (i.e., location data and natural hazard exposure likelihood data). The assumptions associated with the natural hazard exposure data are detailed in PRISM [27]. When the natural hazard exposure information was combined to examine multiple hazard exposure, we assumed that all hazards were of equal potential impact. Therefore, the multiple hazard assessment does not rank the hazards according to potential level of damage or impact.

\section{Results}

The locations of the 454,256 active RCRA sites in the United States are depicted in Figure 1. The majority of these sites are located in the eastern half of the US or along the west coast. The proportion of active RCRA sites vulnerable to each of the twelve natural hazards and the combination of multiple hazards is shown in Table 1. The natural hazards with the highest likelihood of interaction with active RCRA sites are high and low temperature extremes (>99\% of sites), inland flooding $(>99 \%)$, wind events $(95 \%)$, and hail events $(92 \%)$. The natural hazards with the lowest likelihood of interaction with active RCRA sites include hurricanes (11\%), earthquakes (25\%), and coastal flooding (27\%). Over $99 \%$ of active RCRA sites are vulnerable to multiple natural hazards. The metric scores for each natural hazard type are broken up into equal interval classes (refer to "Score class" column) in Table 2 and depict the proportion of vulnerable RCRA sites that experience exposure scores to each of the hazards at specified levels providing information of the potential degree of exposure. For example, only 4254 of 122,852 active RCRA sites exposed to coastal flooding occupied the 4 th or highest "Score class" (i.e., metric score $>75$ ). The majority of RCRA sites experiencing coastal flooding (109,753 sites) occupied the lowest class (i.e., metric score $<25$ ). In contract, the majority of RCRA sites exposed to drought (i.e., 303,716 of 404,452 ) showed metric scores $>75$ while only $2 \%$ of RCRA sites exposed to drought fell in the lowest class (i.e., metric score <25) (Table 2).

Table 1. Number and percentage of RCRA sites in the United States exposed to each natural hazard type and to multiple hazards.

\begin{tabular}{lrr}
\hline Natural Hazard Type & $\begin{array}{l}\text { Number of RCRA Sites Vulnerable to } \\
\text { Natural Hazard Type }\end{array}$ & $\begin{array}{l}\text { Percentage of RCRA Sites Vulnerable to } \\
\text { Natural Hazard Type }\end{array}$ \\
\hline Coastal Flooding & 122,852 & $27.04 \%$ \\
Drought & 404,542 & $89.06 \%$ \\
Earthquakes & 113,810 & $25.05 \%$ \\
Hail & 418,151 & $92.05 \%$ \\
Hurricanes & 50,068 & $11.02 \%$ \\
Inland Flooding & 450,733 & $99.22 \%$ \\
Landslides & 234,335 & $51.58 \%$ \\
High Temperature Extremes & 454,220 & $99.99 \%$ \\
Low Temperature Extremes & 454,183 & $99.98 \%$ \\
Tornadoes & 261,782 & $57.63 \%$ \\
Wildfires & 210,565 & $46.35 \%$ \\
Wind Events & 431,718 & $95.04 \%$ \\
Multiple Natural Hazards & 454,224 & $99.99 \%$ \\
\hline
\end{tabular}


Table 2. RCRA sites with vulnerability metric scores listed by score class $(1=0-25 ; 2=25-50,3=50-75,4=75-100)$ for each natural hazard type and for all hazards, Cumulative Resilience Screening Index (CRSI) Risk Domain score, and overall CRSI score.

\begin{tabular}{|c|c|c|c|c|c|c|c|}
\hline Hazard & $\begin{array}{l}\text { Score } \\
\text { Class }\end{array}$ & $\begin{array}{c}\text { Number of } \\
\text { Sites }\end{array}$ & $\begin{array}{c}\text { Percentage } \\
\text { of Sites }\end{array}$ & Hazard & $\begin{array}{l}\text { Score } \\
\text { Class }\end{array}$ & $\begin{array}{l}\text { Number of } \\
\text { Sites }\end{array}$ & $\begin{array}{c}\text { Percentage } \\
\text { of Sites }\end{array}$ \\
\hline \multirow[t]{5}{*}{ Coastal Flooding } & 1 & 109,753 & $89.34 \%$ & Drought & 1 & 8095 & $2.00 \%$ \\
\hline & 2 & 6610 & $5.38 \%$ & & 2 & 80,138 & $19.81 \$$ \\
\hline & 3 & 2235 & $1.82 \%$ & & 3 & 12,593 & $3.11 \%$ \\
\hline & 4 & 4254 & $3.46 \%$ & & 4 & 303,716 & $75.08 \%$ \\
\hline & ALL & 122,852 & $100.00 \%$ & & ALL & 404,542 & $100.00 \%$ \\
\hline \multirow[t]{5}{*}{ Earthquakes } & 1 & 3651 & $3.21 \%$ & Hail & 1 & 230,643 & $55.16 \%$ \\
\hline & 2 & 7171 & $6.30 \%$ & & 2 & 106,550 & $25.48 \%$ \\
\hline & 3 & 5185 & $4.56 \%$ & & 3 & 33,378 & $7.98 \%$ \\
\hline & 4 & 97,803 & $85.94 \%$ & & 4 & 47,580 & $11.38 \%$ \\
\hline & ALL & 113,810 & $100.00 \%$ & & ALL & 418,151 & $100.00 \%$ \\
\hline \multirow[t]{5}{*}{ Hurricanes } & 1 & 5095 & $10.18 \%$ & Inland Flooding & 1 & 84,822 & $18.82 \%$ \\
\hline & 2 & 35,554 & $71.01 \%$ & & 2 & 251,244 & $55.74 \%$ \\
\hline & 3 & 4112 & $8.21 \%$ & & 3 & 84,288 & $18.70 \%$ \\
\hline & 4 & 5307 & $10.60 \%$ & & 4 & 30,379 & $6.74 \%$ \\
\hline & ALL & 50,068 & $100.00 \%$ & & ALL & 450,733 & $100.00 \%$ \\
\hline \multirow[t]{5}{*}{ Landslides } & 1 & 83,211 & $35.51 \%$ & Temperature $(\mathrm{H})$ & 1 & 41,187 & $9.07 \%$ \\
\hline & 2 & 40,112 & $17.12 \%$ & & 2 & 117,421 & $25.85 \%$ \\
\hline & 3 & 19,165 & $8.18 \%$ & & 3 & 259,374 & $57.10 \%$ \\
\hline & 4 & 91,847 & $39.19 \%$ & & 4 & 36,238 & $7.98 \%$ \\
\hline & ALL & 234,335 & $100.00 \%$ & & ALL & 454,220 & $100 \%$ \\
\hline \multirow[t]{5}{*}{ Temperature (L) } & 1 & 83,324 & $18.35 \%$ & Tornadoes & 1 & 201,187 & $76.85 \%$ \\
\hline & 2 & 200,406 & $44,12 \%$ & & 2 & 30,575 & $11.68 \%$ \\
\hline & 3 & 168,831 & $37.17 \%$ & & 3 & 11,620 & $4.44 \%$ \\
\hline & 4 & 1622 & $0.36 \%$ & & 4 & 18,400 & $7.03 \%$ \\
\hline & ALL & 454,183 & $100.00 \%$ & & ALL & 261,782 & $100.00 \%$ \\
\hline \multirow[t]{5}{*}{ Wildfires } & 1 & 62,166 & $29.52 \%$ & Wind Events & 1 & 166,606 & $38.59 \%$ \\
\hline & 2 & 9618 & $4.57 \%$ & & 2 & 120,699 & $27.96 \%$ \\
\hline & 3 & 9490 & $4.51 \%$ & & 3 & 73,026 & $16.92 \%$ \\
\hline & 4 & 129,291 & $61.40 \%$ & & 4 & 71,387 & $16.54 \%$ \\
\hline & ALL & 210,565 & $100.00 \%$ & & ALL & 431,718 & $100.00 \%$ \\
\hline \multirow[t]{5}{*}{ All Hazards } & 1 & 2792 & $0.61 \%$ & CRSI Risk Domain Score & 1 & 100,559 & $22.14 \%$ \\
\hline & 2 & 81,436 & $17.93 \%$ & & 2 & 125,590 & $27.65 \%$ \\
\hline & 3 & 242,490 & $53.39 \%$ & & 3 & 202970 & $44.69 \%$ \\
\hline & 4 & 127,506 & $28.07 \%$ & & 4 & 25,073 & $5.52 \%$ \\
\hline & ALL & 454,224 & 100.00 & & ALL & 454,192 & $100.00 \%$ \\
\hline
\end{tabular}


Table 2. Cont.

\begin{tabular}{|c|c|c|c|c|c|c|c|}
\hline Hazard & $\begin{array}{l}\text { Score } \\
\text { Class }\end{array}$ & $\begin{array}{c}\text { Number of } \\
\text { Sites }\end{array}$ & $\begin{array}{c}\text { Percentage } \\
\text { of Sites }\end{array}$ & Hazard & $\begin{array}{l}\text { Score } \\
\text { Class }\end{array}$ & $\begin{array}{c}\text { Number of } \\
\text { Sites }\end{array}$ & $\begin{array}{l}\text { Percentage } \\
\text { of Sites }\end{array}$ \\
\hline \multirow[t]{5}{*}{ CRSI Score } & 1 & 452,856 & $99.69 \%$ & & & & \\
\hline & 2 & 1155 & $0.25 \%$ & & & & \\
\hline & 3 & 106 & $0.02 \%$ & & & & \\
\hline & 4 & 139 & $0.03 \%$ & & & & \\
\hline & ALL & 454,256 & $100.00 \%$ & & & & \\
\hline
\end{tabular}

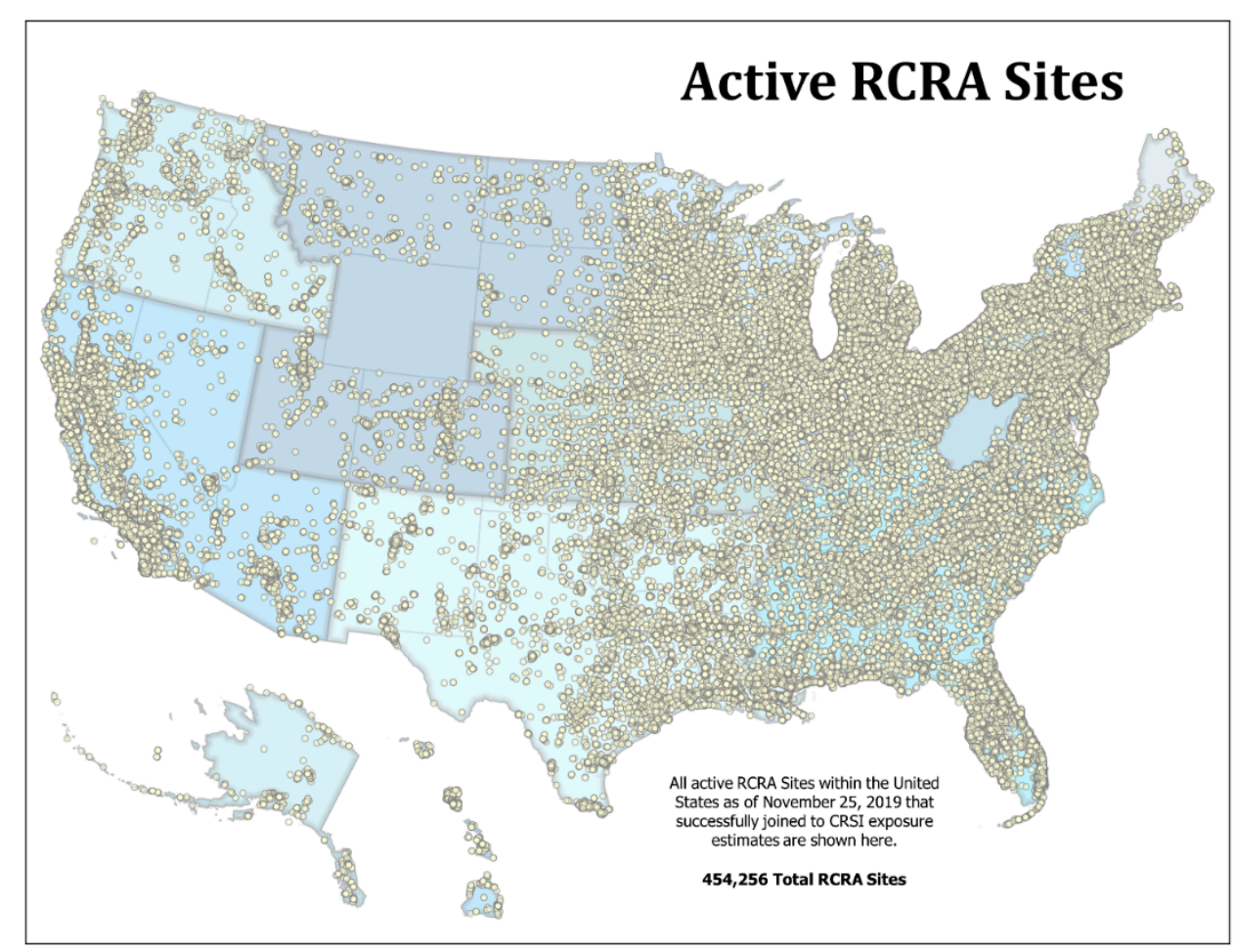

Figure 1. Locations of Resource Conservation and Recovery Act (RCRA) sites throughout the United States.

Natural hazard exposures at active RCRA sites are shown in Figures 2 and 3. These maps show the location of each of the twelve individual natural hazards and the active RCRA sites with the highest exposure class (i.e., metric scores greater than 75). Vulnerability is represented by those active RCRA sites with a specific metric score between 75 to 100 for each natural hazard.

Flood exposures are divided into two categories-coastal (includes sea level rise) and inland. Coastal flooding, as expected, is most likely (metric score >75) at 4254 RCRA sites along two areas of the southeast-coastal Louisiana and south Florida (Figure 2a). Secondary levels of coastal flooding occur along the coastlines of the Gulf of Mexico, MidAtlantic, and the northeast (metric scores $<75$ ). Inland flooding is spread throughout the U.S. at 30,379 active RCRA sites, but most sites with the highest vulnerability appear to be clustered in southern Louisiana, south and big-bend Florida, northern Minnesota, southern Arkansas, northwest Utah, along the Mississippi River, the Dallas and Brownsville regions of Texas, and coastal North Carolina. About $20 \%$ of the sites most vulnerable to inland flooding are distributed throughout the eastern and midwestern states (Figure 2b).

The interaction of 303,716 RCRA sites and high drought exposures is distributed throughout the United States (Figure 2c). Areas with lower probability of extensive drought 
exposure appear to occur at sites in Maine, New Hampshire, and Vermont. High likelihood of wildfire is illustrated at 129,291 RCRA sites in the western states as well as some concentrations in the Oklahoma, Florida, Texas, and the Appalachian Mountains (Figure 2d).

Extremes in low temperature were restricted to 1622 active RCRA sites primarily located in northern Wisconsin and Michigan. As might be expected, extreme high temperatures are pervasive throughout the country at 36,279 sites but some regions indicate a higher probability of extreme temperature exposures at active RCRA sites in southern Alabama and Mississippi, and Louisiana as well as Texas, Oklahoma, Kentucky, and Tennessee (Figure 2e,f). Other RCRA sites experiencing high temperature extremes are Minnesota, Iowa, Arkansas, and New Mexico.
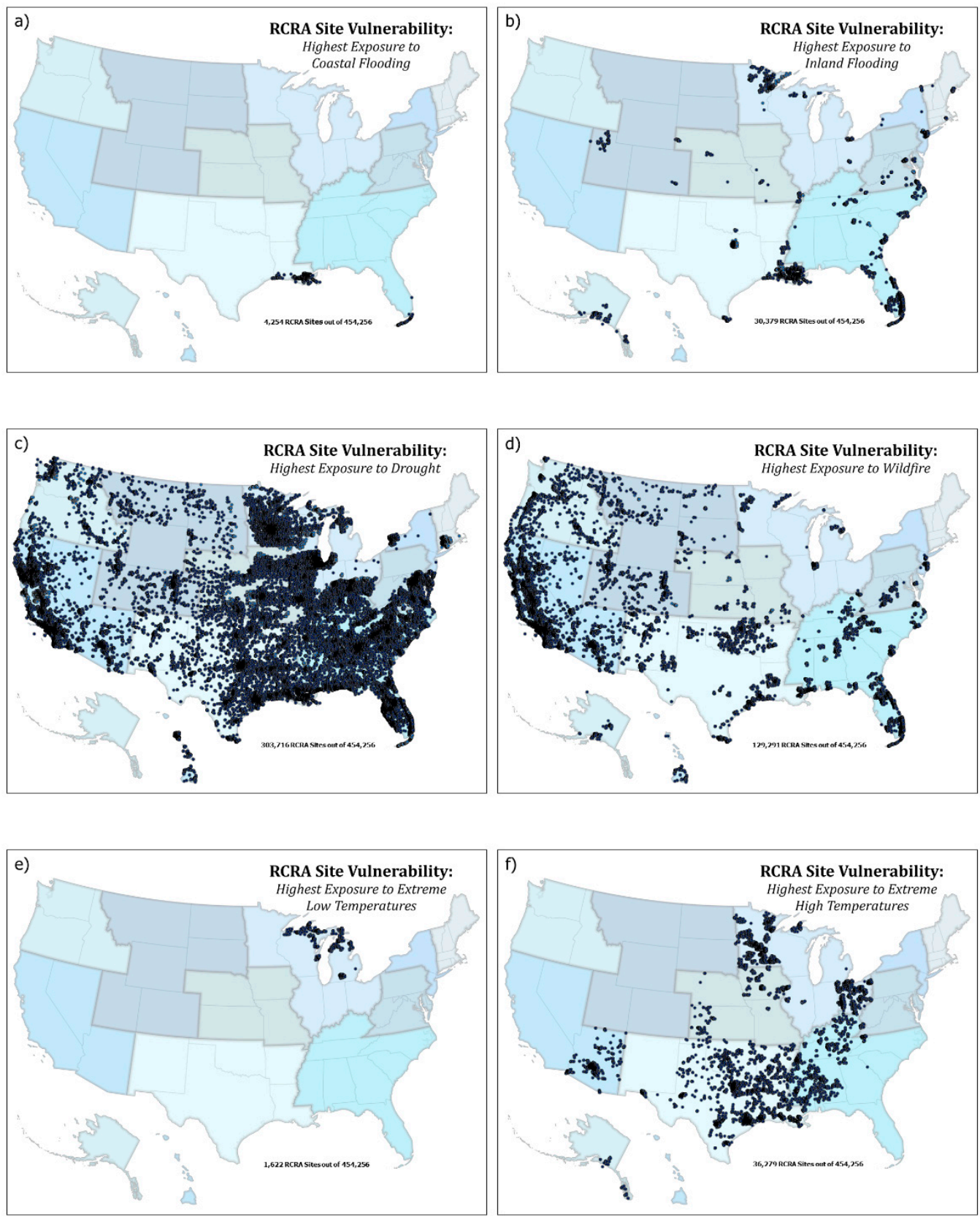

Figure 2. RCRA sites with the 4 th or highest score class (75-100) for indicated natural hazard. (a) coastal flooding; (b) inland flooding; (c) drought; (d) wildfire; (e) extreme low temperature; and, (f) extreme high temperature. 

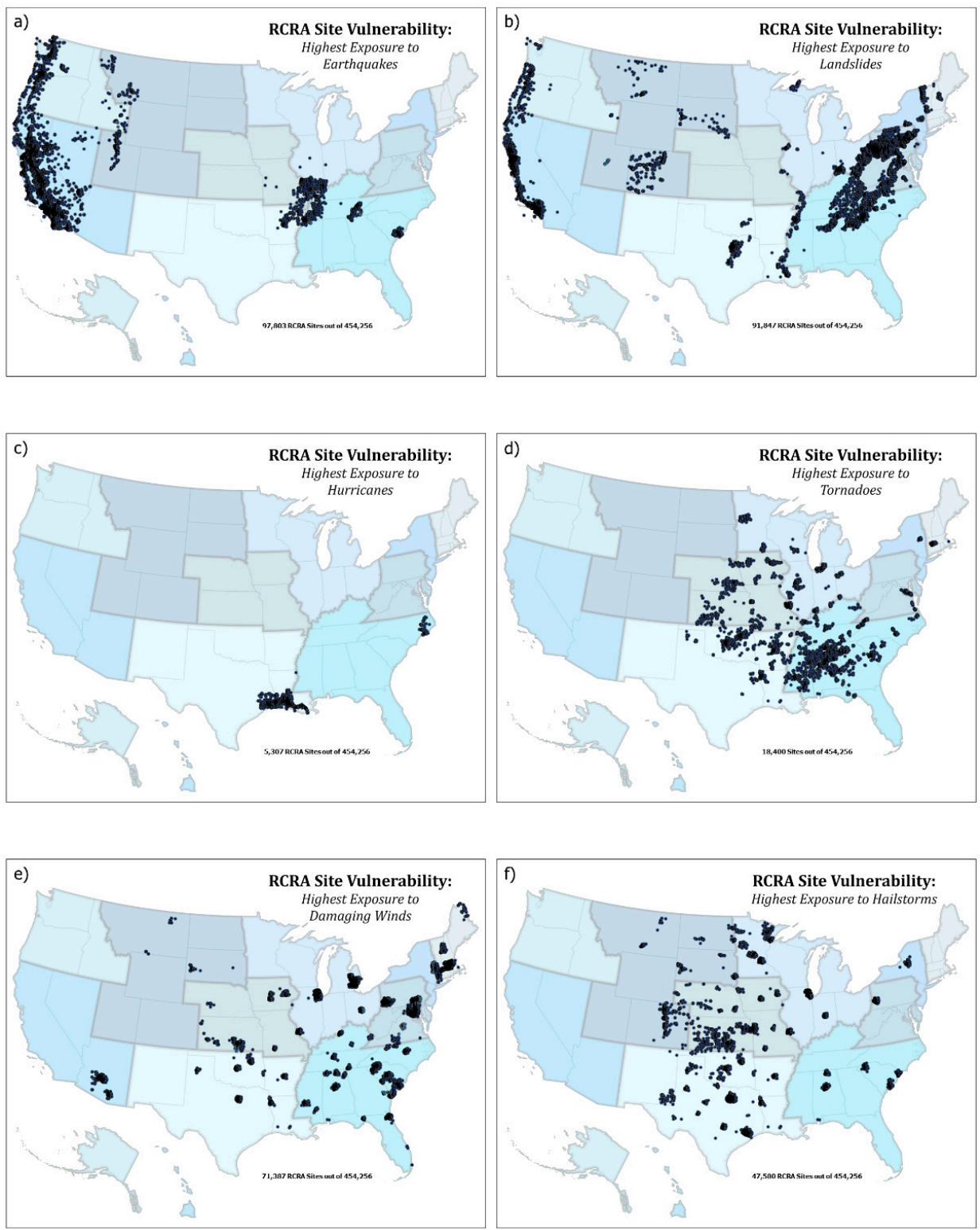

Figure 3. RCRA sites within the 4th or highest score class (75-100) for indicated natural hazard. (a) earthquakes; (b) landslides; (c) hurricanes; (d) tornadoes; (e) damaging winds; and, (f) hailstorms.

Earthquake exposures occur at 97,803 RCRA sites throughout the U.S. but the highest probability is along the western coast and central US (Figure 3a). Other RCRA sites with high exposure to earthquakes include those in Illinois, Kentucky, Missouri, Tennessee, Arkansas with clusters in eastern Tennessee and near Charleston, SC. Similarly, landslides are most common at 81,847 RCRA sites along the Appalachian Mountains, the Mississippi River, the west coast, western Colorado, southern South Dakota, Vermont, and the DallasFort Worth area of Texas. (Figure 3b).

Hurricanes have high probabilities of occurring at 5307 RCRA sites along the Gulf of Mexico coastline between Houston/Galveston and New Orleans and along the North Carolina coast (Figure 3c). Tornadoes have the highest likelihood at RCRA sites in "Tornado Alley" stretching from northern Louisiana and Texas to Nebraska and Iowa (Figure 3d) with secondary regions of high probability occurring at RCRA sites located along the Appalachian Mountains.

Major damaging winds events occur at 71,387 RCRA sites throughout the U.S. (Figure 3e) with the highest probability of damaging winds at sites located in South Carolina, and areas bordering the northern Chesapeake Bay. The highest occurrences of destructive hailstorms 
occur at 47,580 RCRA in the central U.S, from Minnesota/North Dakota to Texas (Figure 3f) with pockets of RCRA sites in coastal South Carolina, northern Alabama, southwestern Pennsylvania, and central New York.

The highest rates of multi-hazard exposure (CSRI indicator) and risk (CSRI domain)multi-hazard exposure and multi-hazard risk-co-occur at 127,506 and 25,073 RCRA sites, respectively, in western states near Los Angeles and San Francisco, CA, Houston and Dallas, TX, Chicago, IL, central Oklahoma, Seattle, WA, Miami, Orlando and Jacksonville, FL, Memphis, TN, Charlotte, NC, and the region between Mobile, AL and New Orleans, LA (Figure 4a). The highest site vulnerability (i.e., $>75$ ) to coastal flooding occurs in southern Louisiana (Figure $4 \mathrm{~b}$ ). Three counties have 400-700 RCRA sites highly vulnerable to nine of the twelve natural hazards (Figure 5). These counties include Shelby County, TN (663 sites), Charleston County, SC (428 sites), and Rapides Parish, LA (483 sites).
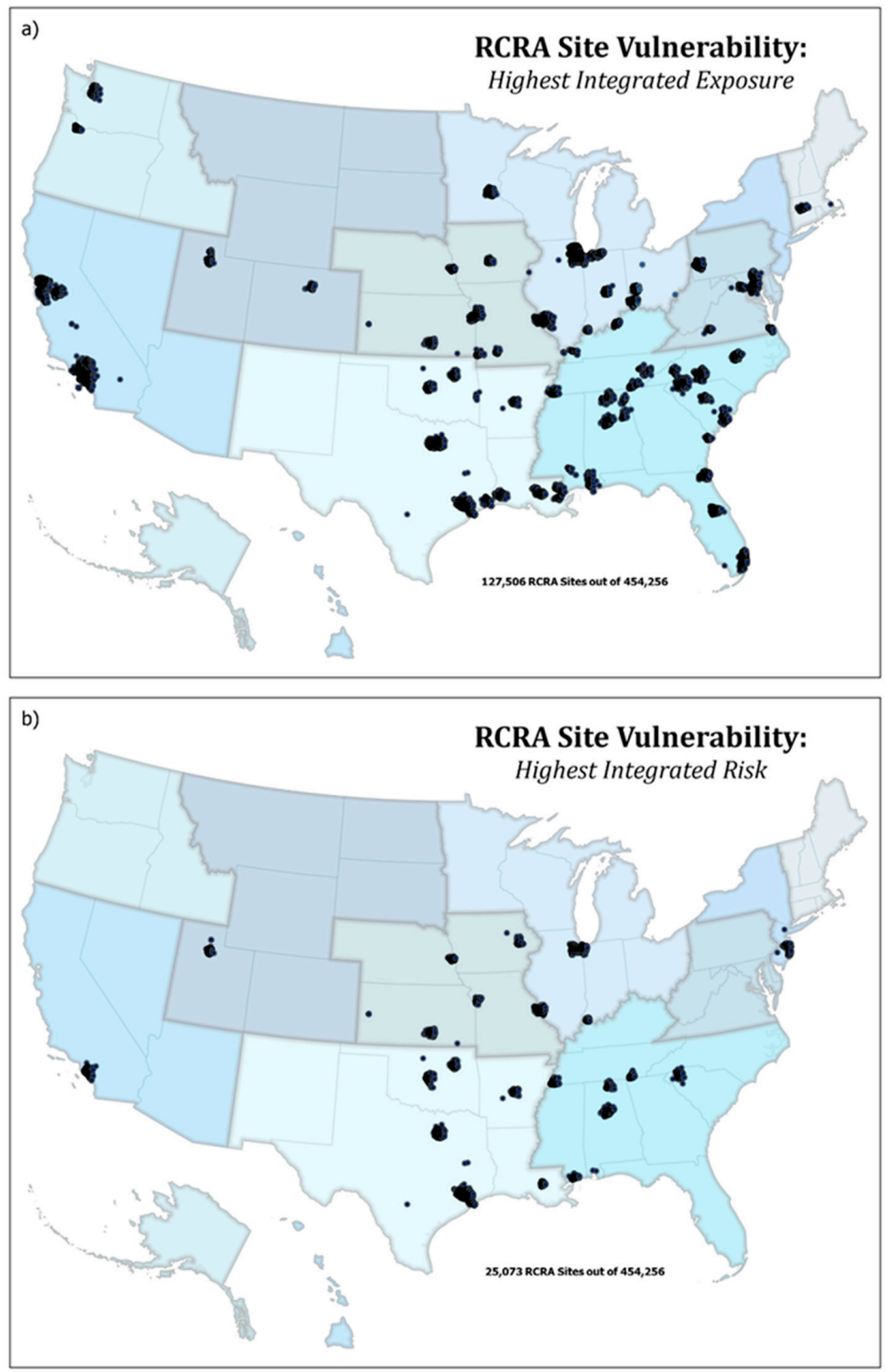

Figure 4. RCRA site locations within the 4th or highest score class (75-100) for multiple natural hazard and the domain score for all natural hazards. (a) highest integrated exposure; (b) highest integrated risk. 


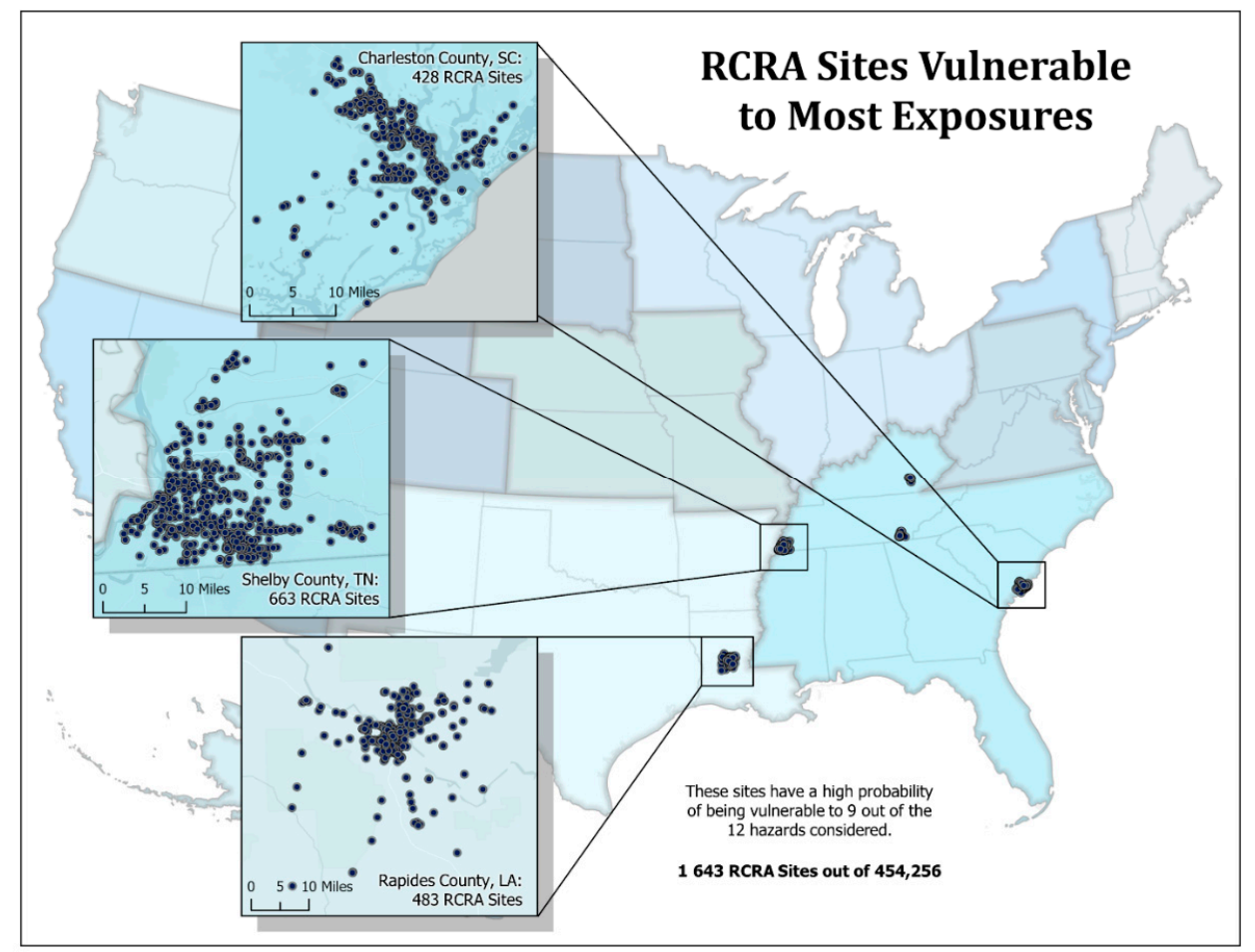

Figure 5. RCRA sites with the highest vulnerability to multiple natural hazards ( 9 of the 12 natural hazards).

RCRA sites in -metropolitan areas that are highly vulnerable to multiple natural hazards (6-8 of the 12 natural hazards) occur throughout the United States (Figure 6a-d). Nearly 15,000 active RCRA sites in areas with populations $<50,000$ throughout the central US are highly likely to be impacted by $6-8$ of the natural hazards. About 60,000 RCRA sitesmultiple natural hazard interactions in metropolitan areas with populations between 50,000 and 250,000 occur in northern Illinois, in Alabama-Mississippi, and southern Louisiana. Similarly, over 92,000 RCRA sites in metropolitan areas with populations between 250,000 and one million interact with 6-8 natural hazards (i.e., Minneapolis/St. Paul, western South Carolina, and the Mississippi-Alabama coast). Finally, for metropolitan areas with populations greater than one million, over 268,000 RCRA sites interact with 6-8 natural hazards; namely, Miami and Jacksonville, FL; Baltimore, MD; Chicago, IL; and, Houston and Dallas, TX.

RCRA sites within eight metropolitan areas in the United States have interactions with 9 of the twelve natural hazards. These include 6735 sites in the Minneapolis/St. Paul area, 5442 sites in the West Palm Beach area, 3015 sites in the District of Columbia/Alexandria/ Arlington area, and 38,560 sites in the Dallas, Houston, Miami, Chicago, and Baltimore areas (Figure 6). 

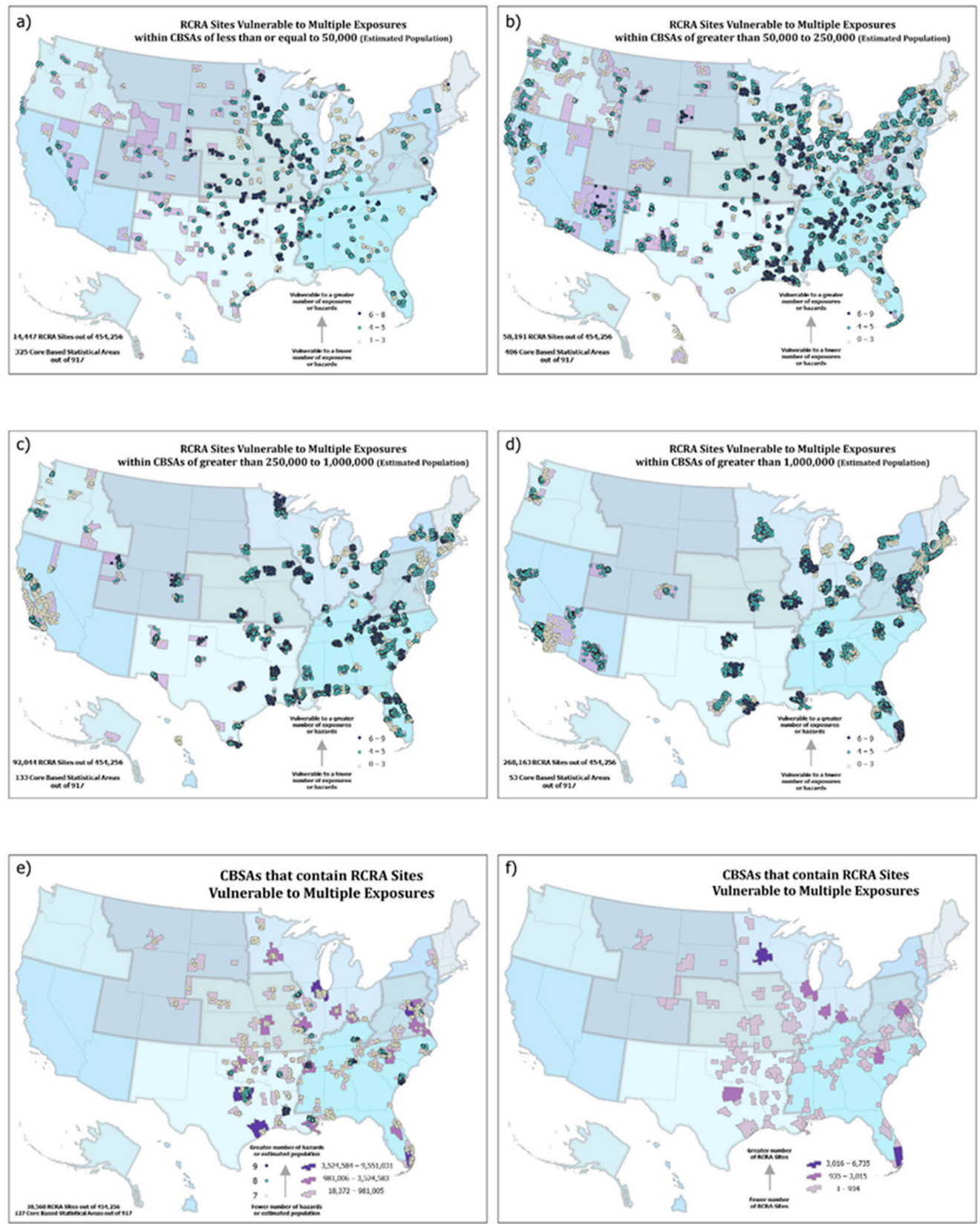

Figure 6. RCRA sites mapped by number of natural hazard exposures in relation to population center size (based on CBSAs).

\section{Discussion}

While RCRA regulations are generally targeted at prevention, remediation waste (i.e., waste generated from the remediation of contamination) is an important part of the RCRA hazardous waste program [29]. As opposed to on-going waste management, remediation activities (overseen by EPA or authorized states) often involve one-time or short-term activities and often less concentrated wastes. The RCRA regulations regarding remediation wastes are necessary to ensure the proper clean-up of contaminated areas [29].

As of 2018, about 3500 active RCRA sites ( $<1 \%$ of the 454,256 active sites) had reached a state of "human exposures under control" and $2632(\sim 0.5 \%)$ had their "performance standards attained" [30]. Estimating the potential natural hazard interactions at active RCRA sites is important for the long- and short-term management and clean-up of these sites. Altering management and clean-up plans to address potential natural hazard exposures can impact the long-term success of the restoration of these sites and, ultimately, 
impact the incorporation of these revitalized sites into the functionality of their adjacent communities. Flooding, wildfires, hurricanes, tornadoes, and earthquakes can represent a great risk to revitalization.

The Government Accounting Office (GAO) reported that most of the nation's RCRA sites are at risk from the impacts of inland flooding and hurricane storm surges that could re-distribute their toxic and non-toxic materials into communities [31]. Over half the people in the U.S. live within a few miles of an RCRA site and about half of these RCRA sites are disproportionately populated by minorities [32]. Toxic and non-toxic contaminants associated with these sites can spread into nearby communities when flooded. Extreme floods, both coastal and inland, are expected to increase in frequency and intensity in the future [33,34], potentially increasing the likelihood of flooding at RCRA sites and the chances that more people may be exposed to flood waters contaminated with hazardous and non-hazardous materials. People most vulnerable to contaminated floodwater exposures from RCRA sites tend to be low-income and minority populations who make up a large proportion of individuals living near these sites [32]. The information and maps reported in this manuscript identify locations with highest site and population vulnerabilities to help with the incorporation of management and mitigation efforts in revitalization planning.

RCRA sites near New Orleans, LA, coastal North Carolina and Houston, TX have all been affected by coastal surges due to hurricanes (Katrina, Florence, and Harvey, respectively) and as a result created extensive amounts of hazardous and non-hazardous wastes that were destined for landfills. Shelby County, TN has 663 active RCRA sites vulnerable to nine of the twelve measured natural hazards, representing the county with the largest number of highly vulnerable RCRA sites. Shelby County includes the metropolitan area of Memphis, TN with a population of over 650,000 and suburban areas with an additional population of about 287,000 . Therefore, nearly one million people could potentially be affected by the interaction of natural hazards and active RCRA sites that could release hazardous and non-hazardous materials. This region is expecting an increase of about 10,000 people and 16,000 tons of municipal solid waste in the next two years [35]. Any natural hazard event or man-made disaster could challenge the county's ability to manage any significant increase in construction and debris [35].

Rapides Parish in Louisiana contains 483 active RCRA sites that are vulnerable to 9 of the 12 measured natural hazards. Rapides Parish has a relatively small population (about $131,000)$ but a larger per capita municipal solid waste burden due to the closure of several military installations in the last decade. The Red River flows through the parish and such was listed as a designated disaster zone due to severe storms and inland flooding [36]. Federal Emergency Management Agency (FEMA) provided assistance to local, tribal, and territorial governments and certain private-non-profit organizations for emergency work and the repair or replacement of disaster-damaged facilities, including RCRA sites [36]. Similar natural hazard damages were seen in Rapides Parish in 2020 due to Hurricane Laura, including RCRA sites [37]. These active RCRA sites manage household hazardous waste, orphan drums, vessels, vehicles, and animal carcasses and can be vulnerable to many of the measured natural hazards listed in this assessment.

Finally, Charleston County, SC houses 428 active RCRA sites that are vulnerable to $3 / 4$ of the natural hazards reported here. The county includes the Charleston and North Charleston metropolitan areas and has a population of over 406,000. Charleston County can experience a loss of life and property of catastrophic proportion due to an array of hazards. Charleston County's Emergency Operations Plan [38] demonstrates the region's vulnerability to multiple natural hazards and their potential interactions with hazardous and non-hazardous releases from active RCRA sites. Impacts of flying debris, release of hazardous and non-hazardous materials, and associated air and water quality events resulting from RCRA site interactions with hurricanes, coastal and inland flooding, wildfires, tornadoes, and wind events are exacerbated by the fact that $20 \%$ of the county's population reside in mobile homes, $16 \%$ of the population is over 65 , and over seven million tourists visit the county annually. 
Smoke and direct chemical releases from fire can impact ecosystems and human health, even at great distances from the burned area. If the burned area includes an RCRA site, even greater issues associated with airborne toxicants are possible. Recent studies have shown that extreme weather conditions, including wildfires, can induce the undesired transport of contaminated sediments into surrounding areas [4]. EPA is supporting communities in the assessment of their vulnerabilities and preparedness to these natural hazards, including unintended releases of hazardous and non-hazardous materials from RCRA, hazardous waste disposal, storage and treatment sites, and industrial sites due to wildfires and flooding [39]. RCRA sites can often contain legacy pollution from multiple industrial sources or landfills. They require complex and resource-intensive remediation, which can take years to complete. Communities living in close proximity to contaminated sites may be affected by wildfire-related environmental stressors such as airborne toxic contamination which can pose health risks. The assessment conducted here shows nearly 130,000 active RCRA sites throughout the U.S. with higher likelihood for exposure to fire. These sites include industrial drums, household wastes, industrial solid wastes, solid wastes from military facilities, and agricultural wastes. Wildfires could volatilize toxicants from any of these types of RCRA remediation sites.

As storms and extreme rainfall events have become more frequent and more intense in recent years, the extent to which these storms will spawn tornadoes is not yet clear [40]. However, if there is more water vapor evaporating, more energy in the atmosphere, and a greater likelihood for stronger heating events that lead to stronger thunderstorms, super cells can be produced that can lead to tornados [41]. While there is no conclusive evidence that climate change is related to small scale phenomena such as tornadoes, lightning, dust storms, and hail, there is ample anecdotal information documenting the increased frequency and intensity of tornadoes [42]. Several of these extreme weather events have affected RCRA sites that contain hazardous wastes [41]. Similarly, natural hazard events can generate massive amounts of hazardous and non-hazardous debris that often is destined for municipal landfills. Communities have to handle these exceptionally large amounts of disaster debris from damaged or destroyed buildings, supplies, trees or other green waste, carcasses, or other materials resulting in RCRA disposal problems relating to hazardous or toxic substances in the debris that can contaminate air, water, land, and food if not handled properly.

Any study of this type has limitations based on the quality of information and availability of exact types of information. This study is no different. As was noted in the text, locational information for RCRA sites was limited in Alaska and was not available from West Virginia or Wyoming. These states have a significant number of RCRA sites. Clearly, West Virginia appears to be in the center of significant landslide activity while Wyoming is likely vulnerable to droughts and wildfires. The assumptions and limitations of the exposure data are explicitly listed in the PRISM manuscript [27] and in CRSI manuscripts [17-19]. One specific limitation of the mapping effort involves the combination of individual natural hazard exposures into a map representing multiple hazard exposures (Figure 4). This figure treats each hazard equally; however, some hazards can create more impact than others. The figure simply depicts the number of exposure types co-occurring at a site. Finally, the hazard data is county based while the site location data represent a specific location within the county. The CRSI data represent a screening likelihood of exposure and may require some more specific investigation.

\section{Conclusions}

The assessment of the co-occurrence of natural hazards and active RCRA site locations demonstrates that there is significant probability of one or more natural hazards interacting with the majority of RCRA sites. The RCRA program remedial actions and recovery programs have progressed beyond basic remediation of its sites to revitalization of the sites into productive and important elements of the local community. Because natural hazard exposure may impact RCRA site remediation, considering their occurrence is prudent when 
developing these remediation and recovery plans as well as management plans. There is ample evidence that these types of natural hazards can impact remediation planning, processes, and, even, after the fact, remediation completion.

The potential occurrence of multiple natural hazards should be considered when developing management plans or planning remediation and restoration at RCRA sites to protect human health and the environment. The information provided in this manuscript enables RCRA managers and planners to incorporate natural hazard exposure into their specific plans. In addition, this information enables multi-exposure considerations, which may be important where mitigation for one type of exposure may interact with the mitigation strategy for a different exposure.

Author Contributions: All authors contributed to the development of this manuscript. K.S. wrote the initial draft; A.L. composed the figures and K.S., A.L., K.B. contributed to editing the manuscript. All authors have read and agreed to the published version of the manuscript.

Funding: This research received no external funding.

Institutional Review Board Statement: This manuscript adheres to the technical and ethical requirements of the U.S. Environmental Protection Agency's Office of Research and Development.

Data Availability Statement: Data is available from the corresponding author and through the U.S. Environmental Protection Agency's Office of Research and Development Science Hub.

Disclaimer: The views expressed in this manuscript are those of the authors and do not necessarily represent the views or policies of the U.S. Environmental Protection Agency. Any mention of trade names, products, or services does not imply an endorsement by the U.S. Government or the U.S. Environmental Protection Agency. The EPA does not endorse any commercial products, services, or enterprises.

Conflicts of Interest: The authors declare no conflict of interest.

\section{References}

1. Binder, S.; Sanderson, L.M. The role of the epidemiologist in natural disasters. Ann. Emerg. Med. 1987, 16, 1081-1084. [CrossRef]

2. Cruz, A.M.; Steinberg, L.J.; Luna, R. Identifying Hurricane-Induced Hazardous Material Release Scenarios in a Petroleum Refinery. Nat. Hazards Rev. 2001, 2, 203-210. [CrossRef]

3. Pielke, R.A., Jr.; Gratz, J.; Landsea, C.W.; Collins, D.; Saunders, M.A.; Musulin, R. Normalized hurricane damage in the United States: 1900-2005. Nat. Hazards Rev. 2008, 9, 29-42. [CrossRef]

4. Turetsky, M.R.; Harden, J.W.; Friedli, H.R.; Flannigan, M.; Payne, N.; Crock, J.; Radke, L.; Flannigan, M.D. Wildfires threaten mercury stocks in northern soils. Geophys. Res. Lett. 2006, 33, 16403. [CrossRef]

5. Rothwell, J.J.; Evans, M.; Liddaman, L.; Allott, T. The role of wildfire and gully erosion in particulate Pb export from contaminated peatland catchments in the southern Pennines, U.K. Geomorphology 2007, 88, 276-284. [CrossRef]

6. Evangeliou, N.; Balkanski, Y.; Cozic, A.; Hao, W.M.; Møller, A.P. Wildfires in Chernobyl-contaminated forests and risks to the population and the environment: A new nuclear disaster about to happen? Environ. Int. 2014, 73, 346-358. [CrossRef]

7. Showalter, P.S.; Myers, M.F. Natural Disasters as the Cause of Technological Emergencies: A Review of the Decade 1980-1989; Natural Hazards Research Center: Boulder, CO, USA, 1992.

8. Showalter, P.S.; Myers, M.F. Natural disasters in the United States as release agents of oil, chemicals, or radiological materials between 1980-1989. Analysis and recommendations. Risk Anal. 1994, 14, 169-182. [CrossRef]

9. Krausmann, E.; Cruz, A.M.; Affeltranger, B. The impact of the 12 May 2008 Wenchuan earthquake on industrial facilities. J. Loss Prev. Process. Ind. 2010, 23, 242-248. [CrossRef]

10. Penning-Rowsell, E.C.; Smith, K. Environmental Hazards: Assessing Risk and Reducing Disaster. Geogr. J. 1993, 159, 349. [CrossRef]

11. Associated Press Judge OKs Deal Over Katrina-Related Oil Spill. Available online: http://www.msnbc,com/id/16892313/ns/ us_news-life/t/judge-oks-deal-over-katrina-related-oil-spill/ (accessed on 30 January 2007).

12. U.S. Environmental Protection Agency (U.S. EPA). Resource Conservation and Recovery Act (RCRA) Overview. 2020. Available online: https: / / www.epa.gov/rcra/resource-conservation-and-recovery-act-rcra-overview (accessed on 20 November 2020).

13. Gaba, J.M. Solid waste and recycled materials under RCRA: Separating chaff from wheat. Ecol. Law Q. 1989, 16, 623-666.

14. Wright, P.R. Testimony before the U.S. House Committee on Appropriations, Interior, Environment and Related Agencies Subcommittee. Available online: https://www.epa.gov/sites/production/files/2020-02/documents/epa-wright_testimonyfeb_5_2020_hac_recycling_hearing.pdf (accessed on 5 February 2020). 
15. Summers, J.K.; Lamper, A.; Buck, K. National Hazards Vulnerability and the Remediation, Restoration and Revitalization of Contaminated Sites-1. Superfund. Environ. Manag. 2020. Submitted for Publication.

16. Summers, J.K.; Smith, L.M.; Harwell, L.C.; Buck, K.D. Conceptualizing holistic community resilience to climate events: Foundation for a climate resilience screening index. GeoHealth 2017, 1, 151-164. [CrossRef] [PubMed]

17. Summers, J.K.; Harwell, L.C.; Buck, K.D.; Smith, L.M.; Vivian, D.N.; Bousquin, J.J.; Harvey, J.E.; Hafner, S.F.; McLaughlin, M.D. Resilience Screening Index (CRSI): An Assessment of Resilience to Acute Meteorological Events and Natural Hazard; EPA600/R-17/238; U.S. Environmental Protection Agency: Washington, DC, USA, 2017.

18. Summers, K.; Harwell, L.C.; Smith, L.M.; Buck, K.D. Measuring Community Resilience to Natural Hazards: The Natural Hazard Resilience Screening Index (NaHRSI)-Development and Application to the United States. GeoHealth 2018, 2, 372-394. [CrossRef] [PubMed]

19. Summers, J.K.; Harwell, L.C.; Buck, K.D.; Smith, L.M.; Vivian, D.N.; Bousquin, J.J.; Harvey, J.E.; Hafner, S.F.; McLaughlin, M.D.; McMillion, C.A. Development of a Cumulative Resilience Screening Index (CRSI) for Natural Hazards: An Assessment of Resilience to Acute Meteorological Events and Selected Natural Hazards; EPA600/R-20/xxx; U.S. Environmental Protection Agency: Washington, DC, USA, 2020.

20. ARUP. City Resilience Framework; The Rockefeller Foundation; ARUP Development International: New York, NY, USA, 2014.

21. Melillo, J.M.; Richmond, T.; Yohe, G.W. Climate Change Impacts in the 11 United States: The Third National Climate Assessment. U.S. Global Change Research Program, 12. 2014. Available online: http:/ /nca2014.globalchange.gov/report (accessed on 20 November 2020).

22. Maco, B.; Bardos, P.; Coulon, F.; Erickson-Mulanax, E.; Hansen, L.J.; Harclerode, M.; Hou, D.; Mielbrecht, E.; Wainwright, H.M.; Yasutaka, T.; et al. Resilient remediation: Addressing extreme weather and climate change, creating community value. Remediat. J. 2018, 29, 7-18. [CrossRef]

23. Burger, J.; Gochfeld, M. Initiating events, functional remediation, and assessment of risk to ecological resources. Ecol. Indic. 2016, 71, 32-40. [CrossRef]

24. Pease, P.; Lecce, S.; Gares, P.; Rigsby, C. Heavy metal concentrations in sediment deposits on the Tar River floodplain following Hurricane Floyd. Environ. Earth Sci. 2006, 51, 1103-1111. [CrossRef]

25. Hooda, P.S.; Alloway, B.J. Effects of time and temperature on the bioavailability of $\mathrm{Cd}$ and Pb from sludge-amended soils. J. Soil Sci. 1993, 44, 97-110. [CrossRef]

26. Nadal, M.; Marquès, M.; Mari, M.; Domingo, J.L. Climate change and environmental concentrations of POPs: A review. Environ. Res. 2015, 143, 177-185. [CrossRef]

27. Buck, K.D.; Summers, K.J.; Hafner, S.; Smith, L.M.; Harwell, L.C.; Summers, J.K. Development of a Multi-Hazard Landscape for Exposure and Risk Interpretation: The PRISM Approach. Curr. Environ. Eng. 2019, 6, 74-94. [CrossRef]

28. Homer, C.; Dewitz, J.; Yang, L.; Jin, S.; Danielson, P.; Xian, G.; Coulston, J.; Herold, N.; Wickham, J.; Megown, K. Completion of the 2011 National Land Cover Database for the conterminous United States-Representing a decade of land cover change information. Photogramm. Eng. Remote Sens. 2015, 81, 345-354.

29. U.S. Environmental Protection Agency. Guidance for Remediation Waste Management at Resource Conservation and Recovery Act (RCRA) Corrective Action Sites. 2020. Available online: https://www.epa.gov/hw/guidance-remediation-wastemanagement-resource-conservation-and-recovery-act-rcra-corrective (accessed on 21 November 2020).

30. U.S. Environmental Protection Agency. Learn about Corrective Action. 2020. Available online: https://www.epa.gov/hw/learnabout-corrective-action\#vmg2030 (accessed on 21 November 2020).

31. GAO (U.S. Government Accounting Office). Hazardous Waste Sites: Improved Effectiveness of Controls at Sites Could Better Protect the Public. GAO-05-163. 2005. Available online: https://www.gao.gov/assets/250/245140.pdf (accessed on 23 November 2020).

32. GAO (U.S. Government Accounting Office). Hazardous and Nonhazardous Waste: Demographics of People Living Near Waste Facilities. GAO/RCED-95-84. 1995. Available online: https://www.gao.gov/assets/160/155134.pdf (accessed on 23 November 2020).

33. Princeton University, Engineering School. Increasing flood risk: '100-year' floods will happen every 1 to 30 years, according to new flood maps. Sci. Dly. 2019. Available online: www.sciencedaily.com/releases/2019/08/190822165010.htm (accessed on 22 November 2020).

34. Marsooli, R.; Lin, N.; Emanuel, K.; Feng, K. Climate change exacerbates hurricane flood hazards along US Atlantic and Gulf Coasts in spatially varying patterns. Nat. Commun. 2019, 10, 1-9. [CrossRef] [PubMed]

35. Memphis Area Association of Governments. Shelby County Solid Waste Needs Assessment. 2019. Available online: https: //maagov.org/wp-content/uploads/2019/03/Shelby_NA_1_18-Revised-3.7.19.pdf (accessed on 23 November 2020).

36. Federal Emergency Management Agency (FEMA). Available online: www.floodsmart.gov (accessed on 8 November 2020).

37. Federal Emergency Management Agency (FEMA). Drive-thru Disaster Recovery Centers Opening in Rapides and Winn Parishes. 2020. Available online: https:/ / www.fema.gov/press-release/20200919/ drive-thru-disaster-recovery-centers-opening-rapidesand-winn-parishes (accessed on 22 November 2020).

38. Charleston County Government Emergency Operations Plan. 2020. Available online: https://www.charlestoncounty.org/ departments/emergency-management/files/EOP.pdf (accessed on 21 November 2020). 
39. Pugh, C.; Whung, P.Y.; Barber, J.; Essoka, J.; Priester, N. EPA Research Highlights -Research to Advance Community Resilience. Em-The Magazine for Environmental Managers. 2019. Available online: https://www.epa.gov/sites/production/files/2019-0 9/documents/research_to_advance_community_resilience.pdf (accessed on 19 November 2020).

40. US Climate Change Science Program (CCSP). Weather and Climate Extremes in a Changing Climate, Regions of Focus: North America, Hawaii, Caribbean, and U.S. Pacific Islands, Synthesis and Assessment Product 3.3. 2008. Available online: http: //www.climatescience.gov/Library/sap/sap3-3/final-report/default.htm (accessed on 20 November 2020).

41. Science Daily. Tornados, Flooding May Warn of Climate Change. Available online: http://www.sciencedaily.com/releases/2008 /06/08062231312.htm (accessed on 22 November 2020).

42. Mooney, C. Is climate change causing an upsurge in US tornadoes? Available online: https://www.newscientist.com/article/ mg19926671-800-is-climate-change-causing-an-upsurge-in-us-tornadoes / (accessed on 21 November 2020). 